\title{
Development of Smartphone Application that Provides Educational Materials on Injury Prevention and Treatment in Hiking
}

\author{
${ }^{1}$ Sigit Dwi Andrianto, ${ }^{2}$ Hysa Ardiyanto, ${ }^{3}$ Erwin Setyo Kriswanto \\ ${ }^{1}$ sigitdwiandrian.2017@student.uny.ac.id, ${ }^{2}$ hysaardiy.2017@student.uny.ac.id, ${ }^{3}$ erwin_sk@uny.ac.id \\ ${ }^{1,2,3}$ Graduate School of Sport Science State University of Yogyakarta Yogyakarta, Indonesia
}

\begin{abstract}
All physical activities carried somerisksofinjury, especially outdoors activities. Safety and injury preventionswerefactorsthat must be consideredin outdoor activities, but the availability of learning media for prevention and treatment for injuries in hiking was insufficient. This study aimedto describe the development of a new smartphone application to promote awareness and knowledge of injury prevention and treatment for beginners in hiking. The new application was developed by conducting procedural research and development. Data were collected by distributing questionnaires containing assessment of product quality and product improvement suggestions. Quantitative data from assessments of material and media experts gained a highly feasible score. After both the limited trial test and large group trial test were completed, the data also got a highly feasible score. A new Android application, Smartpala, developed guidance to prevent and treat injuries after/during hiking. It could be used in limited during hiking due to its limited content.
\end{abstract}

Keywords: injury, hiking, outdoor activity, media

\section{Introduction}

Safety and injury prevention in outdoor activities has become concerns in health research. Injuries in outdoor sports are caused by many factors. Critical information (e.g. pre-existing injuries, behavioral issues, and medication requirements) is one among others. It plays a contributory role in injury incidents as well inadequate risk management and training evaluation systems, inadequate activity policies, poor planning of activities and high participants to staff ratios [1].

Hiking is potential for causing injuries. In 240 sport-related ankle injury cases reported, hiking has the most cases after basketball and soccer [2]. Based on results of study done in America in January 2004-December 2005, the lower limb, upper limb, and head and neck regions are the most commonly injured body areas; while fractures and sprains or strains 
(23.9\%) are the most common diagnoses [3]. These data prove potential, serious injuries that might be experienced by outdoor sport activists.

Meanwhile, there is an increased hiking activity in Indonesia. Data from Balai Taman Nasional Gunung Merapi (BTNGM), as one of the favorite places for beginners, reveal that the number of hikers increases annually by $12.85 \%$. The data were taken in 2011-2015 in the official lines of Selo Boyolali by excluding the illegal lines [4]. The increase is accompanied by the increase of injuries. Those issuebecome our reason to develop educationalmedia containing materials on injury prevention and treatment.

\subsection{Structures}

a. There are increased hiking activities accompanied by increased injury cases. In relation to that issue, information availability is considered as one factor that can affects the prevention of the injuries.

b. This study is important due to limited informational and educational mediain injury prevention and treatment; while hiking activity is a sport with high risks of injuries.

c. Learning media regarding injury prevention and treatment for beginner's hikers are rare. Additionally, learning media in forms of paper-based books are fragile and hence unsuitable to use in outdoor sports.

d. This study discusses the development of android application to provide educational content in both injury prevention and treatment for outdoor activities.

e. The developed application is targeted beginner's hikers in both mild and medium outdoor activities within the context of Indonesia geography.

\section{Related Works/Literary Review}

Existing research on the development of smartphones application for educational purposes covers several aspects. First, it covers the evaluation aspect. Usage of smartphone application for contents related to health and safety is challenged in its content and evidence. The majority of sport medicine-related applications has no name for medical professional involvement [5]. The research result becomes a concern in this research: never give incorrect information.

Another aspect argues that smartphone application is potential for providing education related to physical health and activities, but the effectiveness is not investigated yet. Research developing products in forms of applications should be able to answer the reasons of why the development of the products is urgent. Then, the methods applied must cover the rational of 
the study based on evidence, the development itself, and the testing stages. To increase the likelihood that a newly developed application will be effective, formative research and user testing are required [6]. Those principles are used in this research.

In terms of methods, other research combines the application with other available applications such as open maps and websites integrated with the applications [7].Another study aiming to develop a smartphone application for pre-school children uses a different method based on an interactive children's book flux design [8].The different methods can occur due to different development goals and application development targets in specific population with different characteristic.

\section{Materials\& Methodology}

\subsection{Data}

Data gathered were quantitative data as the primary data and qualitative data in forms of suggestions and recommendations from respondents as secondary data collected by questionnaires. The data provided description of the quality of developed product as well as its effectiveness.

a. Data from the material expert: product quality analyzed from the quality of guidance materials and content aspect.

b. Data from the media expert: quality of display, programming, and literacy.

c. Data from users: used to analyze the display attractiveness, learning easiness, material accuracy, and product usefulness given to hikers.

\subsection{Method}

In this study, the educational media developed was Smartpala, a mobile phoneapplication providing information for preventing and treating injuries in hiking. We targeted the potential users are beginner's hikers aged 16-19 years-old. Outdoor activities they did were in mild to medium category of risks in the context of Indonesia nature.

Steps in this study were: 1) Analyzing potencies and problems by performing preliminary survey to beginners as the respondents and conducting interviews and data collection through questionnaires. It was accompanied by studying relevant literatures and gathering information of content that would be inserted in the application, 2) Designing a starting product in the form of android-based application named Smartpala, 3) Validating the product to both material and media experts. In this step, we proposed preliminary assessments submitted in questionnaires to both experts. Preliminary assessments were done as the consideration to revise the starting 
product. In this step, the revision was continuously performed until the product feasibility was determined by both experts, so that it could be used in a limited scope, 4) After the product feasibility was determined, we conducted a limited trial test to fifteen beginners from Yogyakarta that had been randomly taken by applying the random sampling technique. Instruments to assess the product were questionnaires with the Likert scale and qualitative product suggestions given by the beginners. The suggestions were processed in forms of revision, and (5) results of revision were implemented in the large group to be assessed. In this step, the product was assessed by the entire beginner hikers, fifty people in number, to analyze its feasibility and effectiveness.

\section{Findings and Discussion}

\subsection{Finding}

Findings showed in this research were in forms of the results of validity and reliability tests done to each aspects of question instruments. In addition to that, the product was assessed by media and material experts and beginners.

\subsection{Statements of Findings}

Table 1 shows the results of validity and reliability tests for each aspect.

Table 1.Validity of Display Aspect

\begin{tabular}{|c|l|c|c|}
\hline No. & \multicolumn{1}{|c|}{ Question Items } & r-value & Concl \\
\hline 1. & Readable writing & 0.570 & Valid \\
\hline 2. & Clear instructions for use & 0.449 & Valid \\
\hline 3. & Easily-selected menu & 0.804 & Valid \\
\hline 4. & Easy button use & 0.676 & Valid \\
\hline 5. & Clear button function & 0.691 & Valid \\
\hline 6. & Clear graphic color & 0.591 & Valid \\
\hline & Mean & 0.630 & Valid \\
\hline
\end{tabular}

In the reliability of display aspect, the cronbach's alpha value was 0.845 . 
Table 2. Validity of Learning Aspect

\begin{tabular}{|c|l|c|c|}
\hline No. & \multicolumn{1}{|c|}{ Question Items } & r-value & Concl \\
\hline 1. & Clear materials & 0.631 & Valid \\
\hline 2. & Understandable language & 0.730 & Valid \\
\hline 3. & Clear language & 0.713 & Valid \\
\hline 4. & Related-material pictures & 0.608 & Valid \\
\hline & Mean & 0.671 & Valid \\
\hline
\end{tabular}

In the reliability of learning aspect, the Cronbach'sAlpha value was 0.837 .

Table 3.Validity of Material Aspect

\begin{tabular}{|c|l|c|c|}
\hline No. & \multicolumn{1}{|c|}{ Question Items } & r-value & Concl \\
\hline 1. & Understandable materials & 0.512 & Valid \\
\hline 2. & Challenging/interesting materials & 0.562 & Valid \\
\hline 3. & Useful materials for daily use & 0.425 & Valid \\
\hline 4. & Easily selected guidance menu & 0.500 & Valid \\
\hline 5. & Clear guidance information & 0.440 & Valid \\
\hline 6. & Attractive guidance content & 0.590 & Valid \\
\hline 7. & Interesting display & 0.469 & Valid \\
\hline 8. & $\begin{array}{l}\text { Effective assistance to obtain } \\
\text { information independently }\end{array}$ & 0.281 & Valid \\
\hline & Mean & 0.472 & Valid \\
\hline
\end{tabular}

In the reliability of material aspect, the cronbach's alpha was 0.771 . 
Table 4.Validity of Usefulness Aspect

\begin{tabular}{|c|l|c|c|}
\hline No & \multicolumn{1}{|c|}{ Question Items } & r-value & Concl \\
\hline 1. & Providing positive impacts for its users & 0.692 & Valid \\
\hline 2. & Improving skills for its users & 0.487 & Valid \\
\hline 3. & Assisting in learning & 0.768 & Valid \\
\hline 4. & Broadening knowledge & 0.710 & Valid \\
\hline & Mean & 0.662 & Valid \\
\hline
\end{tabular}

In the reliability of usefulness aspect, the Cronbach'sAlpha value was 0.813. Data in Table $1,2,3$, and 4 suggest that all instrument aspects were valid and reliable. Then, assessment from material and media experts was given. Table 5 displays results of evaluation performed to Smartpala application conducted by the material expert.

Table 5.Assessment from the Material Expert

\begin{tabular}{|c|l|c|c|}
\hline No. & \multicolumn{1}{|c|}{ Assessed Aspect } & Scores & Category \\
\hline 1. & Quality of guidance materials & 4.75 & Highly feasible \\
\hline 2. & Content aspect & 4.7 & Highly feasible \\
\hline & Mean & 4.725 & Highly feasible \\
\hline
\end{tabular}

Table 6 and 7 shows results of evaluation done to Smartpala application performed by the media expert.

Table 6. First Stage Assessment from the Media Expert

\begin{tabular}{|c|l|c|c|}
\hline No. & Assessed Aspect & Score & Category \\
\hline 1. & Display & 3.625 & Feasible \\
\hline
\end{tabular}




\begin{tabular}{|c|l|c|c|}
\hline 2. & Programming & 3.33 & Feasible \\
\hline & Mean & 3.477 & Feasible \\
\hline
\end{tabular}

Table 7. Second Stage Assessment from the Media Expert

\begin{tabular}{|c|l|c|c|}
\hline No. & Assessed Aspect & Score & Category \\
\hline 1. & Display & 4.3 & Highly feasible \\
\hline 2. & Programming & 4 & Feasible \\
\hline & Mean & 4.15 & Highly feasible \\
\hline
\end{tabular}

Table 8 displays results of product assessment in the limited trial test.

Table 8. Assessment of Limited Trial Test

\begin{tabular}{|c|l|c|c|}
\hline No. & Assessed Aspect & Score & Category \\
\hline 1. & Display aspect & 60.1 & Feasible \\
\hline 2. & Learning aspect & 59.25 & Feasible \\
\hline 3. & Material aspect & 62.5 & Highly feasible \\
\hline 4. & Usefulness aspect & 70 & Highly feasible \\
\hline & Mean & 62.96 & Highly feasible \\
\hline
\end{tabular}

Results of product assessment in the large group trial test are shown in Table 9.

Tabel 9. Assessment of Large Group Trial Test

\begin{tabular}{|c|l|c|c|}
\hline No. & Assessed Aspect & Score & Category \\
\hline 1. & Display aspect & 166 & Highly feasible \\
\hline 2. & Learning aspect & 163 & Highly feasible \\
\hline 3. & Material aspect & 161.3 & Highly feasible \\
\hline 4. & Usefulness aspect & 171,5 & Highly feasible \\
\hline & Mean & 165.45 & Highly feasible \\
\hline
\end{tabular}




\subsection{Explanatory Text}

Data in Table 1 showing the display aspect indicate that the mean score for its validity was 0.630 . The score exceeded the table r-value that was 0.279 , validating the question items. The result of reliability calculation in the display aspect was 0.845 . The score exceeded the cronbach's alpha score that was 0.60 , so that the question items in the display aspect were reliable.

Data in Table 2 indicate that the learning aspect shows the mean score for its validity 0.671 , so that it was valid. The result of reliability calculation in the learning aspect was 0.837 , so that it was reliable. Data in Table 3 on the material aspect shows the mean of validity value of 0,472 , implying it was valid. The result of reliability calculation in the material aspect was 0.771 , hence it was reliable. Data in Table 3 on the usefulness aspects indicates the mean of validity value of 0.662 , suggesting its validity. The result of reliability calculation in the usefulness aspect was 0.813 , hence it was reliable.

\subsection{Discussion}

Preliminary research was conducted by distributing questionnaires to twenty beginners in Yogyakarta. Based on the result of distributed questionnaires, among those twenty beginners, $85 \%$ knew how to prevent and treat injuries. However, $80 \%$ of them did not understand the materials because not knowingany appropriate books to read. $75 \%$ of them admitted that conventional books containing materials about the prevention and treatment for injuries (in forms of package or pocket books) were ineffective and unsuitable for outdoor activities. They argued that such books were impractical and fragile due to outdoor conditions. Furthermore, $100 \%$ of them complained that the books were difficult to find and unaffordable.

Furthermore, $85 \%$ of the beginners stated that they had used android mobile phones or the kind. Survey data proposed the fact that $100 \%$ of them revealed that they had more daily interactions with their mobile phones than with books as mobile phones were more flexible to bring. Besides, they also admitted that they needed an android-based application to prevent and treat injuries in hiking sport. Additionally, $90 \%$ of them argued that an application-formed application was more suitable for hiking sport due to its flexibility. In the last survey, 95\% of them preferred the application-based guidance to conventional books as guidance supporting their activity.

In this research, with fifty respondents and the alpha score of 5\%, the r-table value was 0.279. Questioned aspects proposed to respondents were reliable if the cronbach's alpha score was more than 0.60 . Validity and reliability data were processed by using SPSS. In Table 1, 2, 3 , and 4 , all aspects were scored more than 0.279 , validating all questions in the instrument. 
Score of the reliability of four aspects that were display, learning, material, and usefulness was more than 0.60. Therefore, all question items in research instrument were reliable.

Data in Table 5 display the assessment of material expert on the starting product. Instrument used was questionnaires. There were two assessments given by the material aspect: quality of guidance material and content aspect. In the aspect of the quality of guidance material, there were four questions with the mean score categorized as highly feasible. In the content aspect, there were ten questions with the mean score categorized as highly feasible as well. In conclusion, the final result of assessment from the material expert indicated that both aspects were categorized as highly feasible.

Data in Table 6 show assessment by the media expert. There were two assessments conducted by the media expert: the display and programming aspects. In the display aspect, there were sixteen questions with the mean score indicating feasibility. In the programming aspect, there were six questions with the mean score also indicating feasibility. Finally, the final result of assessment by the media expert suggested that both aspects were feasible. However, due to many product evaluations recommended by the media expert, then the product were re-revised.

After product revision, the second assessment categorized the display aspect as highly feasible (Table 7); while the programming aspect was categorized as feasible. The final result of assessment by the media expert categorized both aspects as highly feasibly used. By those results, the product was ready to be tested to the limited group.

Assessments in the limited group trial test covered four assessment aspects. Question items are presented in Table 1, 2, 3, and 4 under these descriptions: the display aspect contained eight questions and was categorized as feasible, learning aspect contained four questions and was categorized as feasible, material aspect contained eight questions and was categorized as highly feasible, and usefulness aspect contained four questions and was categorized as highly feasible as well. Therefore, the mean score could be categorized as highly feasible. Data are displayed in Table 8. However, in the limited trial test assessment, there were many recommendations uttered by the beginners, obliging us to revise the product before testing it to the large group.

The large group trial test assessment generated results in the display, learning, material, usefulness aspects that were categorized as highly feasible. As the conclusion, the final mean result was categorized as highly feasible also. Data are displayed in Table 9. The derived results suggested that Smartpala, as the research product was in accordance with the need and ready to use in limited.

Based on the result of assessing questionnaires given to the beginners, Smartpala was proven to be able to assist them to learn the prevention and treatment for injuries in hiking sport. They also expressed that the usefulness aspect of Smartpala was the most prominent aspect of other aspects. Meanwhile, the learning and material aspects were ranked third and fourth. Although ranked second, the display aspect got recommendations that could not be realized, among them were that several users were interested in video or animated graphics (.gif) and that the application should have also be made for Apple (not for the android only). 
Furthermore, applications developed in mobile phones were more flexible to use than conventional media as books, brochures, and pocket books. The basic barrier was that outdoor conditions did not enable hikers to bring learning media in forms of conventional books. Moreover, the use of mobile phone applications for educational media was highly potential. Undoubtedly, the majority of people had used android-based mobile phones, among them were beginners in hiking dominated by teenagers. Today teenagers that had been familiarized by modern and up-to-date materials were more interested in learning by using sophisticated learning media as well. Besides, Smartpala was an offline android-based application, enabling them to bring it anywhere and everywhere due to its flexibility. If during their activities they found problems related to injuries, the application could be directly functioned as long as the battery and other critical functions are available.

However, the research product had flaws especiallyin its graphic content that were not our original work. Besides, the developed product, Smartpala, might not be suitable with the latest version of android, the version launched after the product was made. It was beyond the standard range that had been implemented from the start.

\section{Conclusion}

This study described the development of mobile phone application as one of the educational attempts to provide information in prevent and treat injuries in hiking. The product developed could be implemented in hiking activities, specifically for learning media for beginners. Moreover, future researchers should simplify the available content or remake it, thus producing a more elaborative content that eases the beginners to learn the presented materials. Future researchers should also cooperate with any competent doctors, because this research was only approved by health experts (not doctors). We expect that this application can be massively produced and used.

\section{Acknowledgement}

The authors wish to acknowledge Dhafin Muktafin, S.T., Caly Setiawan, Ph. D., Nur Rohmah Muktiani, M.Pd., and Fajar Hidayat, S.Pd. for their valuable contributions.

\section{References}


[1] P. M. Salmon, N. Goode, M. G. Lenné, C. F. Finch, and E. Cassell, "Injury causation in the great outdoors: a systems analysis of led outdoor activity injury incidents," Accid. Anal. Prev., vol. 63, pp. 111-120, 2014.

[2] Daniel Tik-Pui Fong, Chi-Yin Man, Patrick Shu-Hang Yung, Shui-Yuk Cheung, KaiMing Chan. "Sport-related ankle injuries attending an accident and emergency department”. Injury, Int. J. Care Injured (2008) 39, 1222-1227. 2008

[3] Adrian H. Flores, BA; Tadesse Haileyesus, MS; Arlene I. Greenspan, Dr.PH, M.PH. "National estimates of outdoor recreational injuries treated in emergency departments, United States 2004-2005.” Wilderness and Environmental Medicine, 19, 9198 (2008) Original Research.

[4] "Jumlah pendaki Merapi terus naik jalur pendakian baru siap dibuka," April 17 $7^{\text {th }}, 2017$. [online]. Available: http://jogja.tribunnews.com/2017/04/17/jumlah-pendaki-merapiterus-naik-jalur-pendakian-baru-siap-dibuka.

[5] S. J. Wong, G. A. Robertson, K. L. Connor, R. R. Brady, and A. M. Wood, "Smartphone apps for orthopaedic sports medicine - a smart move?," BMC Sports Sci. Med. Rehabil., vol. 7, no. 1, pp. 1-7, 2015.

[6] D. Simons, I. De Bourdeaudhuij, P. Clarys, K. De Cocker, C. Vandelanotte, and B. Deforche, "A smartphone app to promote an active lifestyle in lower-educated working young adults: development, usability, acceptability, and feasibility Study," JMIR mHealth uHealth, vol. 6, no. 2, pp. 1-18, 2018.

[7] H. S. Nam et al., "Development of smartphone application that aids stroke screening and identifying nearby acute stroke care hospitals," Yonsei Med. J., vol. 55, no. 1, pp. 25-29, 2014.

[8] L. F. X. A. Campos, J. P. Cavalcante, D. P. Machado, E. Marçal, P. G. de B. Silva, and J. P. M. L. Rolim, "Development and evaluation of a mobile oral health application for preschoolers," Telemed. e-Health, vol. 00, no. 00, pp. 1-7, 2018. 